Article

\title{
Castanopsis lamontii Water Extract Shows Potential in Suppressing Pathogens, Lipopolysaccharide- Induced Inflammation and Oxidative Stress-Induced Cell Injury
}

\author{
Ying Gao ${ }^{1}$, Xinzhong Zhang ${ }^{1}{ }^{\circledR}$, Junfeng Yin ${ }^{1, *}$, Qizhen Du ${ }^{2}$, Youying Tu ${ }^{3, *}$, John Shi ${ }^{4}$ \\ and Yongquan $\mathrm{Xu}{ }^{1, *(\mathbb{D})}$ \\ 1 Tea Research Institute Chinese Academy of Agricultural Sciences, Ministry of Agriculture, \\ Hangzhou 310008, China; yinggao@tricaas.com (Y.G.); zxz.1982@163.com (X.Z.) \\ 2 College of Agricultural and Food Sciences, Zhejiang A \& F University, Linan 311300, China; \\ qizhendu@163.com \\ 3 Department of Tea Science, Zhejiang University, Hangzhou 310058, China \\ 4 Guelph Food Research and Development Center, Agriculture and Agri-Food Canada, Guelph, ON N1G 5C9, \\ Canada; johnshi2006@yahoo.ca \\ * Correspondence: yinjf@tricaas.com (J.Y.); youytu@zju.edu.cn (Y.T.); yqx33@126.com (Y.X.); \\ Tel.: +86-571-8665-0031 (J.Y.); +86-571-8898-2743 (Y.T.); +86-571-8665-0594 (Y.X.)
}

Received: 22 November 2018; Accepted: 9 January 2019; Published: 12 January 2019

check for updates

\begin{abstract}
Castanopsis lamontii is traditionally used to prevent inflammatory diseases such as periodontitis and pharyngitis by residents in southwest China. However, little scientific evidence has been found to support this. In this research, the antibacterial activities of Castanopsis lamontii water extract (CLE) were assessed using the micro-dilution method. The anti-inflammatory and antioxidant activities of CLE were investigated in RAW264.7 cells. Key bioactive compounds in CLE were also explored. Results showed that CLE was capable of inhibiting the periodontitis pathogen Porphyromonas gingivalis and the pharyngitis pathogen $\beta$-hemolytic Streptococcus. It suppressed lipopolysaccharide-induced inflammation in RAW 264.7 cells via inactivating the TLR4/NF- $\mathrm{kB}$ pathway. Besides, it reduced oxidative stress-induced cell injury via scavenging reactive oxygen species. Chemical composition analysis revealed that CLE was rich in epicatechin and procyanidin B2. Further studies confirmed that epicatechin predominantly contributed to the antibacterial activities of CLE, while procyanidin B2 was mainly responsible for the anti-inflammatory activities of CLE. Both compounds contributed to the antioxidant activities of CLE. Acute oral toxicity tests proved that CLE was practically non-toxic. These results provide experimental evidences of the health-beneficial effects of CLE and may help promote the application of CLE in the food and health industries.
\end{abstract}

Keywords: Castanopsis lamontii; epicatechin; procyanidin B2; anti-bacteria; anti-inflammation; antioxidant

\section{Introduction}

Castanopsis lamontii belongs to the Fagaceae family. The buds of Castanopsis lamontii (Figure 1) are traditionally applied as a herb to prevent inflammatory diseases such as periodontitis and pharyngitis. Residents in southwest China used to brew the buds and then drink the infusion to freshen the breath, protect teeth, and keep the pharynx healthy. Previous studies have shown that the leaves, fruits, and seeds of the Fagaceae family are rich in flavonoids, triterpene, triterpenoids, and polyphenols. Extracts from the Fagaceae family have been demonstrated to exhibit various biological activities. For example, the leaf extract from Lithocarpus polystachyus Rehd., containing 
trilobatin and phloridzin, promoted glycogen synthesis in T2DM mice [1]. The seed extract from Lithocarpus dealbata (Miq.) Rehder which was abundant in tannins, showed antidiarrheal potential in animal models [2]. Methanol extracts from the leaves, stem, and root barks of Lithocarpus celebicus showed broad-spectrum antibacterial activities [3]. However, the chemical composition of the buds of Castanopsis lamontii remains unclear and the physiological activities have not yet been demonstrated in the lab.
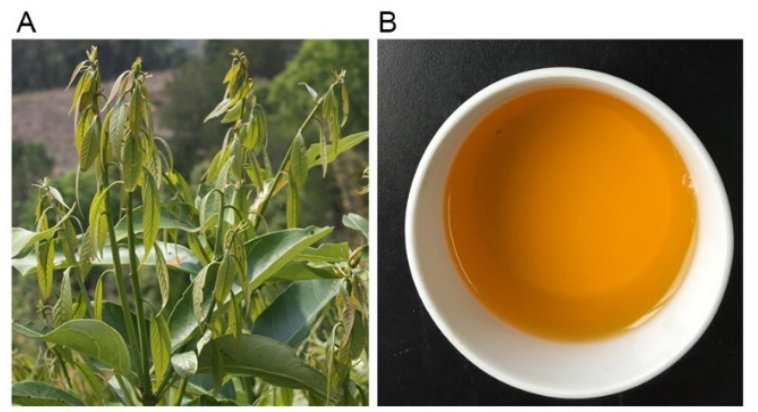

Figure 1. The buds of Castanopsis lamontii (A) and its infusion (B).

In this study, general chemical analysis was carried out to unveil the chemical composition of Castanopsis lamontii water extract (CLE). Ultra-performance liquid chromatography-quadrupoletime-of-flight/mass spectrometry (UPLC-Q-TOF/MS) analysis was used to identify the predominant compounds. The antibacterial, anti-inflammatory and antioxidant activities of CLE were determined to assess its ability to prevent periodontitis and pharyngitis. Key compounds contributed to the physiological activities of CLE were investigated. Acute oral toxicity tests were performed to evaluate its toxicity. The results will deepen the understanding of CLE and provide a theoretical basis for the application of this traditional herb in the food and health industries.

\section{Results and Discussion}

\subsection{Main Chemical Composition of CLE}

The general chemical analysis (Table 1) revealed that almost half of CLE was composed of polyphenols. Surprisingly, the polyphenol content of CLE was even higher than that of most green tea water extracts. Soluble sugars and saponins were the second and third most abundant compounds, respectively. High performance liquid chromatography (HPLC) analysis, together with UPLC-Q-TOF/MS analysis, confirmed that epicatechin (EC) and procyanidin B2 (PB2, or its isomers) were predominant polyphenols in the CLE (Figure 2) (For detailed information about the identification of EC and PB2, please see Supplementary Materials). EC and PB2 (including isomers) accounted for approximately $60 \%(w / w)$ and $17 \%(w / w)$ of total polyphenols in CLE, respectively (Table 2). Gallic acid and caffeine were not detected in the extract (Figure 2). The above results suggested that CLE was an excellent source of polyphenols, especially EC and PB2 (including isomers).

Table 1. Chemical compositions in the water extract from the buds of Castanopsis lamontii (CLE).

\begin{tabular}{cc}
\hline Components & Contents (\%) \\
\hline Polyphenols & $48.38 \pm 0.192$ \\
Soluble sugars & $24.43 \pm 1.944$ \\
Saponins & $12.19 \pm 0.312$ \\
Amino acids & $2.520 \pm 0.168$ \\
Polysaccharides & $2.184 \pm 0.048$ \\
Proteins & $1.440 \pm 0.240$ \\
Flavonoids & $1.056 \pm 0.000$ \\
Caffeine & Not detected \\
\hline
\end{tabular}



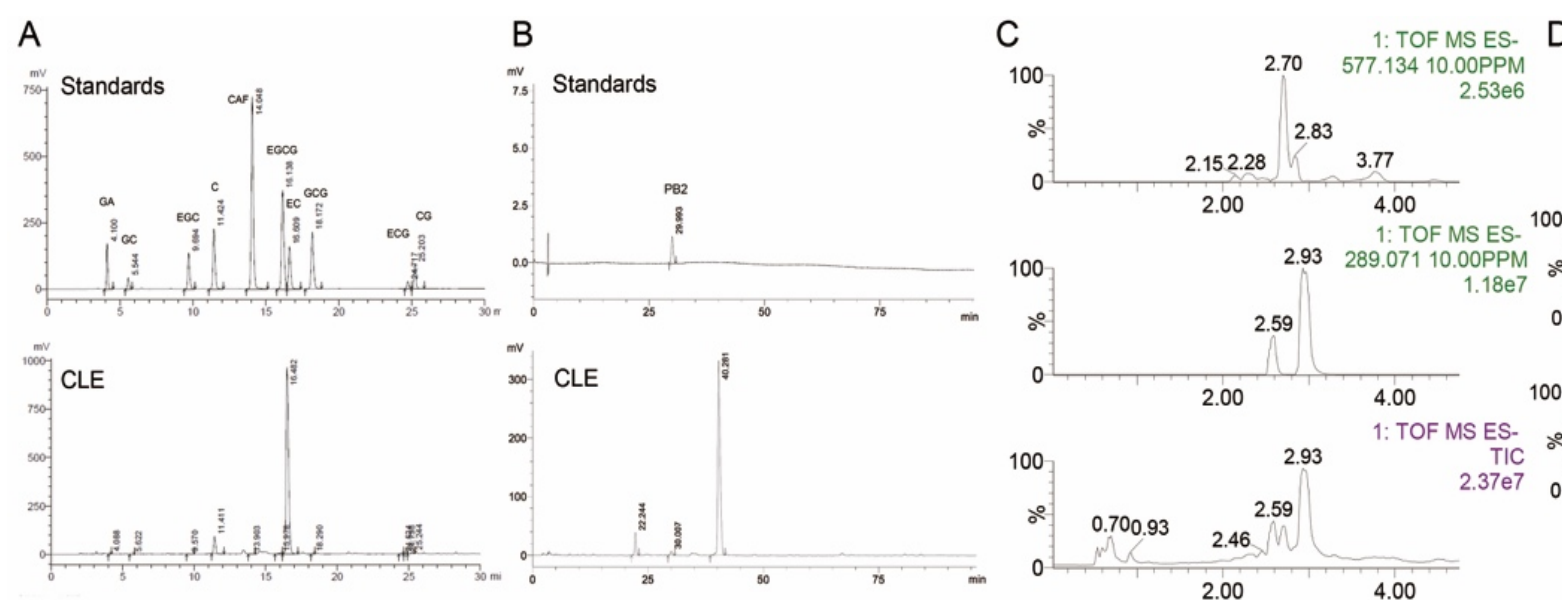

\section{D}
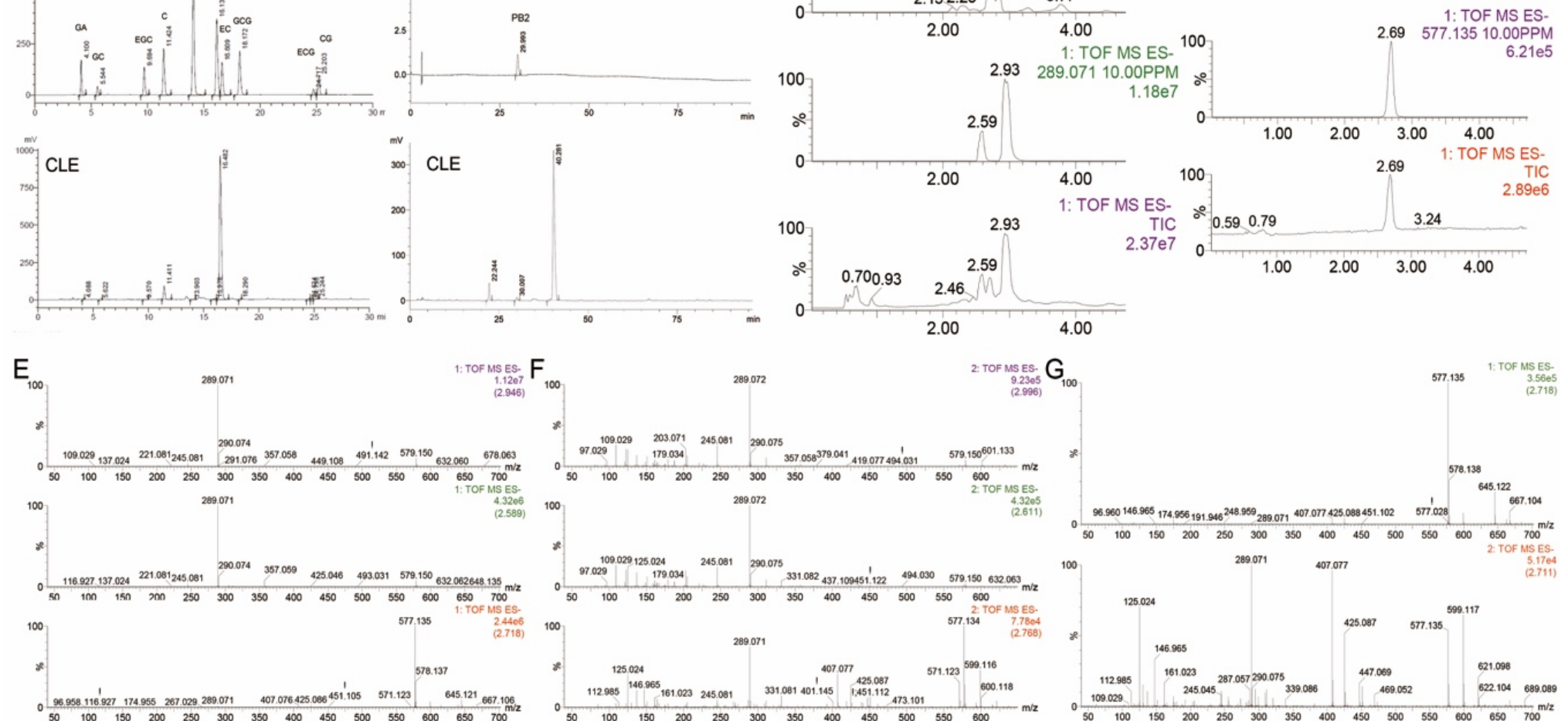

Figure 2. HPLC-UV and ultra-performance liquid chromatography-quadrupole-time-of-flight/mass spectrometry (UPLC-Q-TOF/MS) analysis of the Castanopsis lamontii water extract (CLE). (A) HPLC chromatograms of gallic acid, caffeine and catechins; (B) HPLC chromatograms of procyanidin B2 (PB2); (C) Total ion chromatogram of CLE (lower), ion chromatogram of CLE at $m / z 289.071$ (middle) and ion chromatogram of CLE at $m / z 577.134$ (upper) at ESI ${ }^{-}$; (D) Total ion chromatogram of the PB2 standard (lower) and ion chromatogram of the PB2 standard at $m / z 577.134$ (upper); (E) ESI ${ }^{-}$-MS spectra of peaks at retention time $2.718 \mathrm{~min}$ for PB2 (lower), $2.589 \mathrm{~min}$ for C (middle), and $2.946 \mathrm{~min}$ for EC (upper), respectively; (F) ESI ${ }^{-}$-MS/MS spectra of peaks at retention time 2.768 min for PB2 (lower), $2.611 \mathrm{~min}$ for C (middle), and $2.996 \mathrm{~min}$ for EC (upper), respectively; (G) ESI ${ }^{-}$-MS/MS spectra of the peak at retention time 2.718 min for the PB2 standard (lower) and $\mathrm{ESI}^{-}$-MS spectra of the peak at retention time $2.711 \mathrm{~min}$ for the PB2 standard (upper). 
Table 2. Concentrations of catechins, procyanidin B2, and gallic acid in CLE solution $(400 \mu \mathrm{g} / \mathrm{mL})$.

\begin{tabular}{cc}
\hline Components & Concentrations $(\mu \mathrm{g} / \mathrm{mL})$ \\
\hline Epicatechin (EC) & $120.1 \pm 1.1$ \\
Procyanidin B2 (PB2) (including isomers) & $34.4 \pm 3.2$ \\
Catechin (C) & $9.6 \pm 0.5$ \\
Gallic acid (GA) & Not detected \\
Gallocatechin (GC) & $0.1 \pm 0.0$ \\
Epigallocatechin (EGC) & $0.5 \pm 0.0$ \\
Epigallocatechin gallate (EGCG) & $0.3 \pm 0.0$ \\
Gallocatechin gallate (GCG) & $0.1 \pm 0.0$ \\
Epicatechin gallate (ECG) & $0.1 \pm 0.0$ \\
Catechin gallate (CG) & $0.2 \pm 0.0$ \\
\hline
\end{tabular}

\subsection{Antibacterial Activities of CLE}

Periodontitis and pharyngitis belong to infectious diseases. Periodontitis is a set of inflammatory diseases that affects the tissues surrounding the teeth, which can lead to loosening and even loss of teeth and fetid breath. Pharyngitis is a type of upper respiratory tract infection, typically resulting in a sore throat and fever. Porphyromonas gingivalis and $\beta$-hemolytic Streptococcus are principal pathogens of periodontitis and pharyngitis, respectively $[4,5]$. In this study, the inhibitory effects of CLE against Porphyromonas gingivalis, $\beta$-hemolytic Streptococcus, and two common opportunistic pathogenic bacteria, namely Staphylococcus aureus and Escherichia coli, were tested. According to the results, the minimum inhibitory concentrations (MICs) of CLE against Porphyromonas gingivalis, $\beta$-hemolytic Streptococcus, Staphylococcus aureus, and Escherichia coli were $0.625,1.25,2.5$, and $1.25 \mathrm{mg} / \mathrm{mL}$, respectively (Table 3).

Table 3. Minimum inhibitory concentrations (MICs) of CLE against pathogens and opportunistic pathogens.

\begin{tabular}{cccccccccc}
\hline Concentrations of CLE $(\mathrm{mg} / \mathrm{mL})$ & $\mathbf{0}$ & $\mathbf{0 . 1 5 6}$ & $\mathbf{0 . 3 1 3}$ & $\mathbf{0 . 6 2 5}$ & $\mathbf{1 . 2 5}$ & $\mathbf{2 . 5 0}$ & $\mathbf{5 . 0 0}$ & $\mathbf{1 0 . 0}$ \\
\hline Porphyromonas gingivalis & + & + & + & - & - & - & - & - \\
$\beta$-hemolytic Streptococcus & + & + & + & + & - & - & - & - \\
Staphylococcus aureus & + & + & + & + & + & - & - & - \\
Escherichia coli & + & + & + & + & - & - & - & - \\
\hline "+" means visible growth of the bacteria
\end{tabular}

Previous studies have revealed that EC and procyanidins exhibit antibacterial properties. EC-enriched Fagopyrum cymosum extracts were capable of inhibiting $\beta$-hemolytic Streptococcus and Streptococcus pneumoniae in vitro and in vivo [6]. Proanthocyanidin-enriched grape seed extract inhibited the endotoxin release of Porphyromonas gingivalis and the MIC of the extract against Porphyromonas gingivalis was $0.8 \mathrm{mg} / \mathrm{mL}$ [7]. Here, we proved that the MICs of EC against Porphyromonas gingivalis, $\beta$-hemolytic Streptococcus, Staphylococcus aureus, and Escherichia coli were $1.25,1.25,1.25$, and $1.25 \mathrm{mg} / \mathrm{mL}$, respectively (Table 4). No obvious antibacterial effects of PB2 were detected under the experimental conditions, indicating that the MICs of PB2 against these four bacteria was greater than $1.25 \mathrm{mg} / \mathrm{mL}$, respectively (Table 4). This hinted that EC might be responsible for the antibacterial activities of CLE.

The MIC of EC against Porphyromonas gingivalis was higher than that of CLE, suggesting the possibility of the presence of other antibacterial components in the CLE. Based on the chemical analysis, CLE contained substantial amounts of saponins. Saponins are strong surfactant agents and can interrupt the stability of the cell membrane and increase cell leakage, leading to the death of bacteria. Saponins derived from various plants have been shown to exhibit antibacterial activities, even at very low concentrations [8]. Thus, saponins present in CLE might also possess antibacterial properties. Nevertheless, further studies are needed to verify this. 
Table 4. The MICs of EC and PB2 against pathogens and opportunistic pathogens.

\begin{tabular}{cccccccccc}
\hline Concentrations of EC $(\mathbf{m g} / \mathrm{mL})$ & $\mathbf{0}$ & $\mathbf{0 . 0 7 8}$ & $\mathbf{0 . 1 5 6}$ & $\mathbf{0 . 3 1 3}$ & $\mathbf{0 . 6 2 5}$ & $\mathbf{1 . 2 5}$ & $\mathbf{2 . 5 0}$ & $\mathbf{5 . 0 0}$ \\
\hline Porphyromonas gingivalis & + & + & + & + & + & - & - & - \\
$\beta$-hemolytic Streptococcus & + & + & + & + & + & - & - & - \\
Staphylococcus aureus & + & + & + & + & + & - & - & - \\
Escherichia coli & + & + & + & + & + & - & - & - \\
\hline Concentrations of PB2 $(\mathbf{m g} / \mathrm{mL})$ & $\mathbf{0}$ & $\mathbf{0 . 0 2 0}$ & $\mathbf{0 . 0 3 9}$ & $\mathbf{0 . 0 7 8}$ & $\mathbf{0 . 1 5 6}$ & $\mathbf{0 . 3 1 3}$ & $\mathbf{0 . 6 2 5}$ & $\mathbf{1 . 2 5}$ \\
\hline Porphyromonas gingivalis & + & + & + & + & + & + & + & + \\
B-hemolytic Streptococcus & + & + & + & + & + & + & + & + \\
Staphylococcus aureus & + & + & + & + & + & + & + & + \\
Escherichia coli & + & + & + & + & + & + & + & + \\
\hline
\end{tabular}

"+" means visible growth of the bacteria, while "-" means no visible growth of the bacteria.

\subsection{Anti-Inflammatory Activities of CLE}

Lipopolysaccharide (LPS) is a prototypical endotoxin and induces a strong response from normal animal immune systems. It binds the toll-like receptor 4 (TLR-4), activates inflammatory signaling pathways, promotes the secretion of pro-inflammatory cytokines, nitric oxide (NO) and eicosanoids in several types of immune cells, and finally causes classical symptoms of inflammation. Nuclear factor- $\mathrm{kB}(\mathrm{NF}-\mathrm{kB})$ is one of the downstream proteins in the TLR-4 pathway. Activation of NF- $\mathrm{kB}$ leads to the transcription of inducible nitric oxide synthase (iNOS) and cyclooxygenase-2 (COX-2), and these two proteins are key enzymes involved in the production of NO and prostaglandins, respectively. To evaluate the anti-inflammatory activities of CLE, RAW264.7 cells were treated with LPS and CLE, and then the expression of TLR-4 pathway-related proteins and the release of NO, prostaglandin E2 (PGE2), and tumor necrosis factor $\alpha$ (TNF- $\alpha$ ) were determined. The results elucidated that CLE decreased the release of NO, PGE2, and TNF- $\alpha$ (Figure 3A-C). CLE also lowered the levels of TLR-4, p-NF-kB (p65), iNOS, and COX-2 (Figure 3D). This implied that CLE suppressed LPS-stimulated inflammation by inactivating the TLR-4/NF-kB/iNOS and TLR-4/NF- $\mathrm{kB} / \mathrm{COX}-2$ pathways.

PB2, a B type proanthocyanidin widely present in plants (e.g., grape seeds, apples, cocoa beans, litchi, and hawthorn), displays anti-inflammatory activities in many ways [9-11]. It markedly elevated the expression of a TLR-4 negative regulator, thus blocking LPS-induced expression of cell surface molecules, activation of mitogen-activated protein kinases (MAPKs, e.g., ERK1/2, p38, JNK), translocation of NF- $\mathrm{kB}$ (p65), and production of pro-inflammatory cytokines in macrophages [12]. By preventing the activation of NF- $\mathrm{KB}$ and MAPKs, PB2 also suppressed the expression of COX-2 [13]. Similar to PB2, EC also exerts anti-inflammatory activities [11]. It inhibited the production of NO, PGE2, TNF- $\alpha$, and interleukin- 6 in LPS-induced macrophages by inactivation of the NF- $\mathrm{KB}, \mathrm{MAPKs}$, and JAK2/STAT3 pathways [14]. In this research, PB2 and EC at concentrations identical to the concentrations of PB2 and EC in $400 \mu \mathrm{g} / \mathrm{mL}$ CLE were demonstrated to decrease LPS-stimulated up-regulation of TLR4, p-NF-kB (p65), COX-2, iNOS, NO, PGE2, and TNF- $\alpha$ (Figure 3) in RAW 264.7 cells. Compared with EC, PB2 showed much more potency in suppressing the LPS-stimulated inflammatory response. It indicated that PB2 was vital for the anti-inflammatory activities of CLE while EC played a subordinate role. 

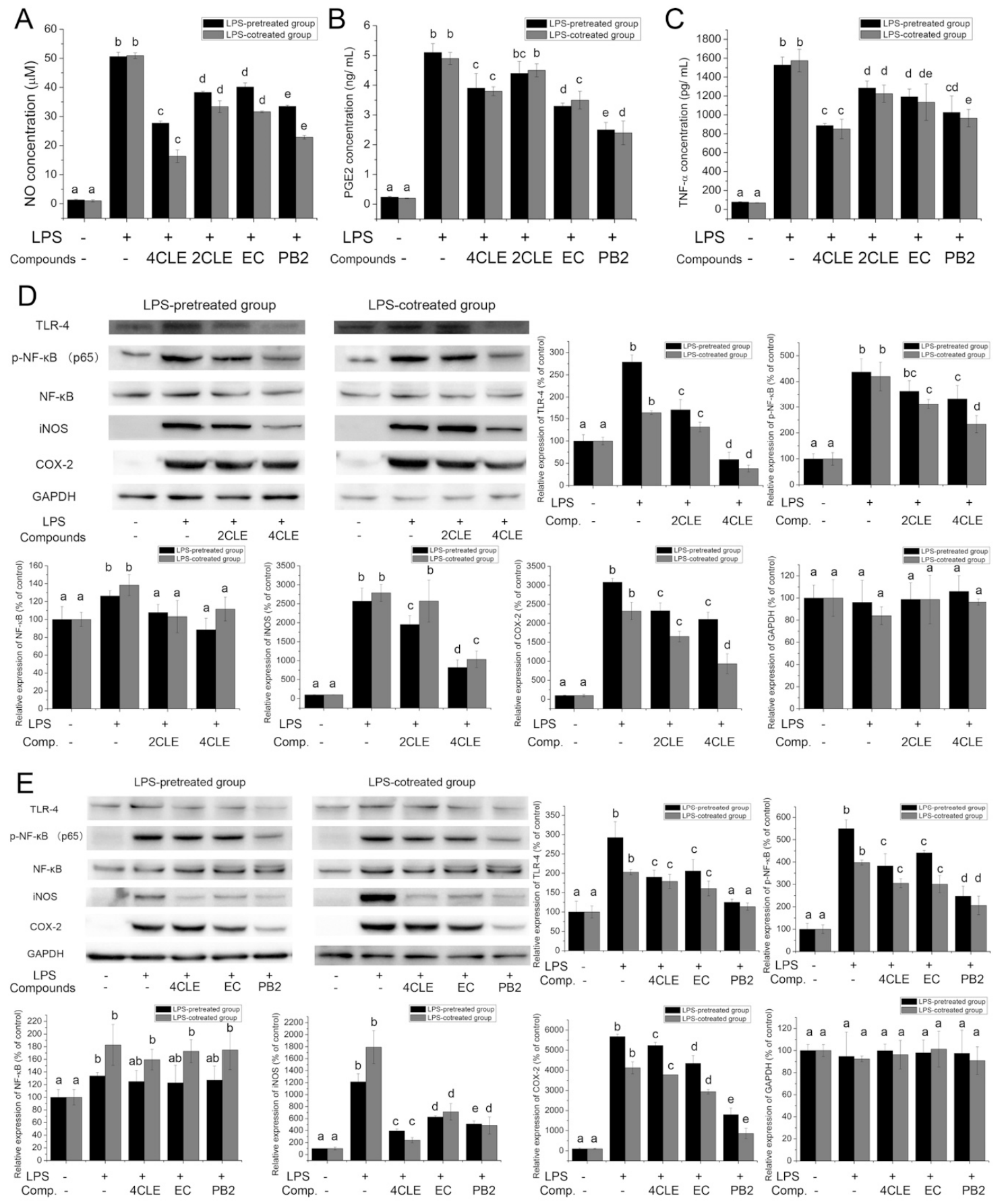

Figure 3. Anti-inflammatory activities of CLE, EC, and PB2. (A-C) The effects on nitric oxide (NO), prostaglandin E2 (PGE2), and tumor necrosis factor $\alpha$ (TNF- $\alpha$ ) secretion of LPS-pretreated or co-treated RAW 264.7 cells; (D,E) The impacts on the expression of toll-like receptor 4 (TLR4), p-NF- $\mathrm{B}$ (p65), NF- $\mathrm{kB}$ (p65), inducible nitric oxide synthase (iNOS), and cyclooxygenase-2 (COX-2). Glyceraldehyde-3-phosphate dehydrogenase (GAPDH) served as the loading control. The same letter within each column indicates no significant difference $(p>0.05)$. Comp. is short for compounds. 4CLE (2CLE) is short for 400 (200) $\mu \mathrm{g} / \mathrm{mL}$ CLE. The dosages of EC and PB2 were identical amount of EC and PB2 in $400 \mu \mathrm{g} / \mathrm{mL}$ CLE, which were $120 \mu \mathrm{g} / \mathrm{mL}$ and $34.4 \mu \mathrm{g} / \mathrm{mL}$, respectively.

\subsection{Antioxidant Activities of CLE}

Inflammation stimulates cellular reactive oxygen species (ROS) production [15]. Excessive ROS in turn enhance inflammation. In addition, overproduction of ROS causes injury and even necrosis 
of macrophages, resulting in an uncontrolled release of cell contents into the extracellular space, which deteriorates inflammation.

In this study, the effects of CLE on rescuing or protecting cells from oxidative stress-induced damage were investigated. Lactate dehydrogenase (LDH) is an enzyme found in almost all living cells and is released when cell damage occurs [16]. By measuring the LDH activities in the cell culture supernatant, the severity of $\mathrm{H}_{2} \mathrm{O}_{2}$-induced cell damage can be determined. According to the results, CLE decreased $0.5 \mathrm{mM} \mathrm{H}_{2} \mathrm{O}_{2}$ caused-cell damage in pretreated and cotreated models (Figure $4 \mathrm{~A}$ ). CLE was more potent in preventing $\mathrm{H}_{2} \mathrm{O}_{2}$-mediated cell damage than in rescuing it. Intracellular ROS levels were also measured. A cell-permeable non-fluorescent probe, $2^{\prime}, 7^{\prime}$-dichlorodihydrofluorescein diacetate (DCFH-DA), is hydrolyzed by mitochondrial esterase to form DCFH, which is then oxidized by ROS to form the cell-impermeable fluorescent compound $2^{\prime}, 7^{\prime}$-dichlorofluorescein (DCF). In this study (Figure 4B), CLE significantly inhibited $\mathrm{H}_{2} \mathrm{O}_{2}$-induced increase of intracellular ROS levels.
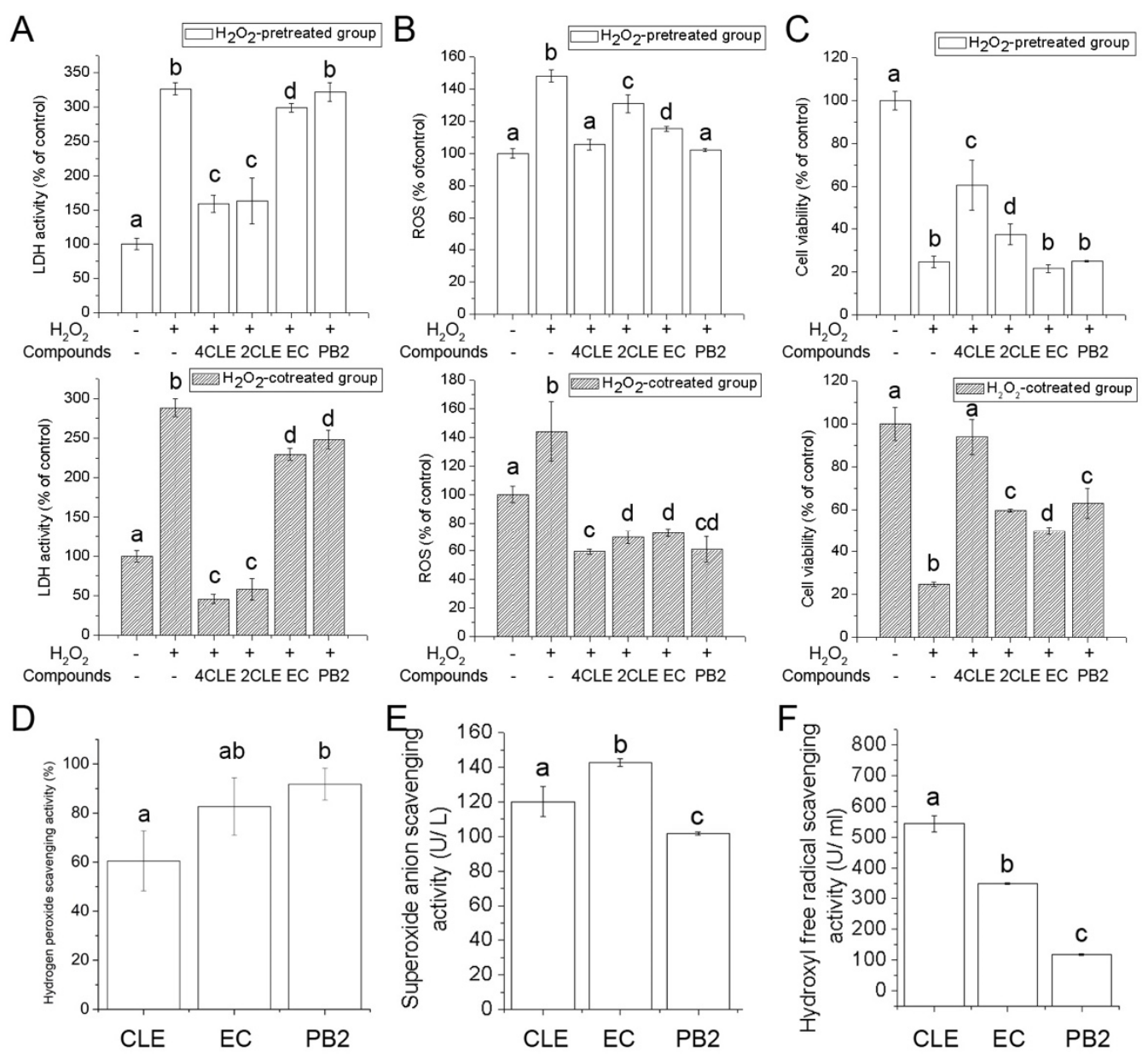

Figure 4. Antioxidant activities of CLE, EC, and PB2. (A) The effects on the lactate dehydrogenase (LDH) release of $0.5 \mathrm{mM} \mathrm{H} \mathrm{O}_{2}$-pretreated or co-treated RAW 264.7 cells; (B) The effects on the intracellular reactive oxygen species (ROS) levels of $0.5 \mathrm{mM} \mathrm{H}_{2} \mathrm{O}_{2}$-pretreated or co-treated RAW 264.7 cells; (C) The effects on the viability of $1 \mathrm{mM} \mathrm{H}_{2} \mathrm{O}_{2}$-pretreated or co-treated RAW 264.7 cells; (D-F) The hydrogen peroxide and free radical scavenging activities of CLE, EC, and PB2. The same letter within each column indicates no significant difference $(p>0.05)$. 4CLE (2CLE) is short for 400 (200) $\mu \mathrm{g} / \mathrm{mL}$ CLE. The dosages of EC and PB2 were identical amount of EC and PB2 in $400 \mu \mathrm{g} / \mathrm{mL}$ CLE, which were $120 \mu \mathrm{g} / \mathrm{mL}$ and $34.4 \mu \mathrm{g} / \mathrm{mL}$, respectively.

When damage caused by oxidative stress is too severe to be repaired, cells can no longer remain living. The MTT assay is a colorimetric assay used to measure the number of living cells. Results from 
the MTT assay illustrated that the viability of $1 \mathrm{mM} \mathrm{H}_{2} \mathrm{O}_{2}$-pretreated and co-treated cells was significantly increased by CLE, suggesting that CLE could reduce the cytotoxicity of $\mathrm{H}_{2} \mathrm{O}_{2}$ (Figure 4C). Compared with the $\mathrm{H}_{2} \mathrm{O}_{2}$-pretreated group, the viability of the $\mathrm{H}_{2} \mathrm{O}_{2}$-cotreated group was significantly higher. The results of the in vitro free radical-scavenging tests (Figure $4 \mathrm{D}-\mathrm{F}$ ) suggested that one of the possible reasons was that CLE could directly react with $\mathrm{H}_{2} \mathrm{O}_{2}$ to lower the concentration of $\mathrm{H}_{2} \mathrm{O}_{2}$ in the culture medium and CLE was capable of scavenging free radicals, such as the superoxide anion and hydroxyl free radical.

Considerable researches have shown that EC and PB2 are effective antioxidants. They not only scavenge free radicals, but also activate antioxidant enzymes [17]. In this research, EC and PB2 were confirmed as contributors to the antioxidant activities of CLE (Figure 4). Although the concentration of PB2 used in these experiments $(34.4 \mu \mathrm{g} / \mathrm{mL})$ was much lower than that of EC $(120 \mu \mathrm{g} / \mathrm{mL})$, their antioxidant activities in cell models were not significantly different. Considering that the free radical scavenging activity of PB2 was weaker than EC at the concentration used in this experiment, it could be assumed that PB2 exhibited its antioxidant activity via mechanisms other than directly reacting with free radicals, possibly by having an impact on antioxidant enzymes. According to previous studies, PB2 was capable of increasing the activities of antioxidant enzymes, including superoxide dismutase (SOD), catalase (CAT), and glutathione peroxidase (GSH-Px) [18,19]. Furthermore, it was noteworthy that the antioxidant activities of CLE were much higher than those of EC or PB2 in cell models, suggesting that there were other antioxidant components existing in CLE. Previous research has illustrated that some plant-derived polysaccharides and saponins have antioxidant activities and are able to protect cells from oxidative damage [20,21]. The saponins and polysaccharides present in CLE might also have antioxidant activities. However, the roles of these compounds have not been studied in the present research and further work is needed to determine their functions.

\subsection{Acute Oral Toxicity of CLE}

Acute oral toxicity test showed that no mice died during the observation period after a single administration of CLE at the dosage of $20 \mathrm{~g} / \mathrm{kg}$ body weight (Table 5). No acute poisoning symptoms were observed during the observation period. No abnormalities of organs in size, color, shape, consistency or other characteristics were detected by the gross examination. According to the Chinese Standard of GB 15193.3-2014, CLE was regarded as practically non-toxic.

Table 5. Acute oral toxicity of CLE.

\begin{tabular}{ccccc}
\hline Gender & Initial Average Body Weight $(\mathbf{g})$ & Final Average Body Weight $(\mathbf{g})$ & Death & LD $_{\mathbf{5 0}}(\mathbf{g} / \mathbf{k g})$ \\
\hline Female & $20.6 \pm 1.3$ & $28.7 \pm 1.5$ & 0 & $>20.0$ \\
Male & $20.1 \pm 1.2$ & $30.4 \pm 1.6$ & 0 & $>20.0$ \\
\hline
\end{tabular}

\subsection{Effects of CLE, EC and PB2 on Normal RAW 264.7 Cells}

The effects of CLE, EC, and PB2 on RAW 264.7 cells without the presence of LPS and $\mathrm{H}_{2} \mathrm{O}_{2}$ were also studied. Generally, CLE, EC, or PB2 alone at the test concentration didn't significantly affect the viability, LDH activities, ROS levels, and inflammatory-related pathways of RAW 264.7 cells. These results were presented in the Supplementary Materials.

\section{Materials and Methods}

\subsection{Materials}

The buds of Castanopsis lamontii were collected in the Dehong Area, Mang City, Yunnan Province, China $\left(24^{\circ} 17^{\prime} 12^{\prime \prime} \mathrm{N}, 98^{\circ} 23^{\prime} 6^{\prime \prime} \mathrm{E}\right)$ and identified by Botanist Keke Chen, Kunming Institute of Botany, Chinese Academy of Sciences. The hydroxyl free radical assay kit and superoxide anion assay kit were obtained from Nanjing Jiancheng Bioengineering Institute. The LDH cytotoxicity assay 
kit, NO assay kit, primary antibodies (p-NF- $\mathrm{kB}$ (p65) (Product \#AN371), NF- $\mathrm{kB}$ (Product \#AF0246), GAPDH (Product \#AF0006), and secondary antibodies (Product \#A0216 \& A0208) were purchased from Beyotime Institute of Biotechnology, Co. Ltd. (Haimen, China) Primary antibodies (TLR4 (Product \#14358S), COX-2 (Product \#12282), iNOS (13120S) were purchased from Cell Signaling Technology, Co. Ltd. (Danvers, MA, USA). The MTT cell proliferation and cytotoxicity assay kit was purchased from Nanjing KeyGEN Bio-TECH, Co. Ltd. (Nanjing, China) The PGE2 ELISA kit and the TNF- $\alpha$ ELISA kit were purchased from Jiangsu Meimian industrial Co., Ltd. (Zhangjiagang, China) Chemical standards used in HPLC analysis, UPLC-Q-TOF/MS analysis and cell assays were purchased from Sigma-Aldrich Co., Ltd. (St. Louis, MO, USA).

\subsection{Preparation of $C L E$}

The buds of Castanopsis lamontii were dried, powdered, and filtered through a 60-mesh screen. The powder was extracted with distilled water (powder weight: water volume $=1: 100$ ) for $20 \mathrm{~min}$ at $80{ }^{\circ} \mathrm{C}$ and centrifuged at $8000 \mathrm{rpm}$ for $10 \mathrm{~min}$ to remove powder residues. The supernatant was collected and vacuum dried.

\subsection{Determination of Chemical Composition}

The total phenolic, free amino acid, and water extract contents were measured according to the Chinese Standard of GB/T 8313-2008, GB/T 8314-2013 and GB/T 8305-2013, respectively.

The total flavonoid content was determined using the Dowd method with modifications. Briefly, $10 \mathrm{~mL} 1 \%$ aluminium trichloride $\left(\mathrm{AlCl}_{3}\right)$ was mixed with $0.5 \mathrm{~mL}$ sample solution and incubated at room temperature for $10 \mathrm{~min}$. The absorbance was measured at $420 \mathrm{~nm}$ using a UV-VIS-NIR spectrophotometer (UV-3600, Shimadzu Co., Ltd., Kyoto, Japan).

The total soluble sugar content was estimated using the anthrone-sulfuric acid colorimetric method. Briefly, $1 \mathrm{~mL}$ sample solution was mixed with $4 \mathrm{~mL}$ anthrone-sulfuric acid $(2 \mathrm{mg} / \mathrm{mL})$ and reacted at $100{ }^{\circ} \mathrm{C}$ for $10 \mathrm{~min}$. After cooling to room temperature, the absorbance was read at $620 \mathrm{~nm}$.

To measure the polysaccharide content, the sample solution was mixed with $95 \%$ ethanol $(v / v=1: 5)$, maintained at $4{ }^{\circ} \mathrm{C}$ overnight, and centrifuged to spin down the polysaccharides. Samples were then analyzed using the anthrone-sulfuric acid method.

The protein content was measured using the Bradford method [22].

To determine the total saponin content [23], the sample solution was extracted three times with water-saturated n-butanol. The n-butanol layer was collected and washed three times with ammonia water. Then, the n-butanol layer was dried and the residues were dissolved in methanol for measurement. A $200 \mu \mathrm{L}$ sample solution was added to $0.5 \mathrm{~mL} \%$ vanillin-alcohol solution and $3 \mathrm{~mL}$ $70 \%$ sulfuric acid and the reaction system was incubated at $60{ }^{\circ} \mathrm{C}$ for $10 \mathrm{~min}$. After cooling to room temperature, the absorbance was read at $540 \mathrm{~nm}$.

\subsection{HPLC Analysis}

The catechins, gallic acid, and caffeine contents were analyzed according to a previously published method [24].

The PB2 content was examined using a previously reported method which could distinguish eight B-type procyanidin dimers [25].

\subsection{UPLC-Q-TOF/MS Analysis}

An UPLC-Xevo G2-S Q-TOF/MS system (Waters, Milford, MA, USA), equipped with an AC-QUITY UPLCTM I-class solvent manager, an ACQUITY UPLCTM sample manager-FTN, an AC-QUITY UPLCTM column manager, and a Xevo G2-S Q-TOF /MS with a Zspray electrospray ion source at real time mass correction, was used for the determination. Data collection and system control was performed using the Waters MassLynx 4.1 software workstation (Waters Corporation, Milford, MA, USA). 
The UPLC HSS T3 column (100 mm $\times 2.1 \mathrm{~mm}, 1.7 \mu \mathrm{m}$, Waters, Milford, MA, USA) was used for the separation. The gradient separation was carried out using $0.1 \%$ formic acid in water and $0.1 \%$ formic acid in acetonitrile as mobile phases $\mathrm{A}$ and $\mathrm{B}$, with the flow rate at $0.4 \mathrm{~mL} / \mathrm{min}$ for $30 \mathrm{~min}$ and the column temperature at $40{ }^{\circ} \mathrm{C}$. When the gradient elution changed from 0 to $2 \mathrm{~min}$, $\mathrm{B}$ increased lin-early from $5 \%$ to $20 \%$; from 2 to $3.3 \mathrm{~min}$, B was $20 \%$; from 3.3 to $5 \mathrm{~min}$, B increased linearly from $20 \%$ to $30 \%$; from 5 to $7 \mathrm{~min}$, B increased linearly from $30 \%$ to $40 \%$; from 7 to $10 \mathrm{~min}$, B increased linearly from $40 \%$ to $50 \%$; from 10 to $12 \mathrm{~min}$, B increased linearly from $50 \%$ to $100 \%$; from 12 to $14.5 \mathrm{~min}$, B was $100 \%$; from 14.5 to $14.6 \mathrm{~min}$, B reduced linearly from $100 \%$ to $5 \%$; from 14.6 to $16 \mathrm{~min}$, B was $5 \%$.

The Q-TOF/MS analyses were performed under the positive and negative ionization full scan modes with a capillary electrospray voltage of $3 \mathrm{kV}$ and $1.5 \mathrm{kV}$, respectively, a cone voltage of $40 \mathrm{~V}$, an offset voltage of $80 \mathrm{~V}$, a source temperature of $150{ }^{\circ} \mathrm{C}$, a desolvation gas of nitrogen at $99.95 \%$ with the desolvation temperature at $350{ }^{\circ} \mathrm{C}$ and a flow rate of $800 \mathrm{~L} / \mathrm{h}$, and a cone gas of nitrogen at $99.95 \%$ with a flow rate of $50 \mathrm{~L} / \mathrm{h}$. The scan range and acquisition rate was at $m / z 50-1200$ and $2 \mathrm{spectra} / \mathrm{s}$. The calibration reference ion was at $m / z 556.2771$ for $\mathrm{ESI}^{+}$and $m / z 554.2665$ for $\mathrm{ESI}^{-}$.

\subsection{Determination of Minimum Inhibitory Concentrations (MIC) against Bacteria}

The MICs against Porphyromonas gingivalis (ATCC 33277), $\beta$-hemolytic Streptococcus (CMCC (B) 32210), Staphylococcus aureus (CMCC (B) 26003) and Escherichia coli (CMCC (B) 44102) were determined using the micro-dilution method [26].

\subsection{Determination of Anti-Inflammatory Activities in LPS-Treated RAW264.7 Cells}

Mouse macrophage RAW264.7 cells were seeded into 96-well plates at a density of $1.5 \times 10^{4}$ per well in RPMI-1640 medium incorporating 10\% fetal bovine serum (FBS). Cells were grown in a humidified incubator containing $5 \% \mathrm{CO}_{2}$ at $37^{\circ} \mathrm{C}$. After overnight growth, cells were treated with $500 \mathrm{ng} / \mathrm{mL}$ LPS for $2 \mathrm{~h}$ prior to adding $200 \mu \mathrm{g} / \mathrm{mL}$ CLE, $400 \mu \mathrm{g} / \mathrm{mL}$ CLE, $120 \mu \mathrm{g} / \mathrm{mL}$ epicatechin (EC) (equivalent to the concentration of EC in $400 \mu \mathrm{g} / \mathrm{mL}$ CLE), or $34.4 \mu \mathrm{g} / \mathrm{mL}$ PB2 (equivalent to the concentration of PB2 in $400 \mu \mathrm{g} / \mathrm{mL}$ CLE) for $24 \mathrm{~h}$ to test the protective activity. Cells were co-treated with $500 \mathrm{ng} / \mathrm{mL}$ LPS and CLE/EC/PB2 for $24 \mathrm{~h}$ to test the rescuable activity. The NO, PGE2, and TNF- $\alpha$ concentrations were measured using the NO assay kit, PGE2 ELISA kit, and TNF- $\alpha$ kit, respectively.

\subsection{Western Blot}

The Western blot assay was conducted using a previously published method [27]. GAPDH served as the loading control.

\subsection{Determination of Antioxidant Activities in Hydrogen Peroxide-Treated RAW264.7 Cells}

RAW264.7 cells were seeded into 96-well plates at a density of $1.5 \times 10^{4}$ per well in RPMI-1640 medium incorporating 10\% FBS. After overnight growth, cells were treated with $0.5 \mathrm{mM}$ hydrogen peroxide $\left(\mathrm{H}_{2} \mathrm{O}_{2}\right)$ for $1 \mathrm{~h}$ prior to adding $200 \mu \mathrm{g} / \mathrm{mLCLE}, 400 \mu \mathrm{g} / \mathrm{mLCLE}, 120 \mu \mathrm{g} / \mathrm{mL}$ EC (equivalent to the concentration of EC in $400 \mu \mathrm{g} / \mathrm{mL}$ CLE), or $34.4 \mu \mathrm{g} / \mathrm{mL}$ PB2 (equivalent to the concentration of PB2 in $400 \mu \mathrm{g} / \mathrm{mL}$ CLE) for $24 \mathrm{~h}$ to test the protective activities. Cells were co-treated with $0.5 \mathrm{mM} \mathrm{H}_{2} \mathrm{O}_{2}$ and CLE/EC/PB2 for $24 \mathrm{~h}$ to test the rescuable activity. Then the LDH release assay were conducted using the LDH cytotoxicity assay kit, according to the manufacturer's instructions. The production of intracellular ROS was monitored by a multi-functional microplate reader (Thermo Scientific Varioskan Flash, Waltham, MA, USA) after the cells were incubated with $2^{\prime}, 7^{\prime}$-dichlorofluorescin diacetate (DCHF-DA). To evaluate the protective or rescuable activity of CLE against oxidative stress-induced cell death, RAW 264.7 cells were treated with $1 \mathrm{mM} \mathrm{H}_{2} \mathrm{O}_{2}$ for $1 \mathrm{~h}$ prior to adding CLE/EC/PB2, or co-treated with $1 \mathrm{mM} \mathrm{H}_{2} \mathrm{O}_{2}$ and CLE/EC/PB2 for $24 \mathrm{~h}$. Then the cell viability was assessed using a MTT cell proliferation assay kit. 


\subsection{Determination of Free Radical Scavenging Activities}

Hydrogen peroxide scavenging activity, superoxide anion-scavenging activity, and hydroxyl free radical-scavenging activity were measured using a hydrogen peroxide assay kit, a superoxide anion assay kit, and a hydroxyl free radical assay kit according to the manufacturer's instructions, respectively.

\subsection{Acute Oral Toxicity Tests}

Ten female and ten male ICR mice (body weight 18-22 g) were used for the acute oral toxicity tests (License No. SCXK (Zhe) 2014-0008 and SYXK (Zhe) 2014-0008). The tests were carried out according to the Chinese Standard GB 15193.3-2014. Briefly, the mice were housed in a controlled environment (12 h light-dark cycle, temperature of $22 \pm 2{ }^{\circ} \mathrm{C}$, relative humidity of $50 \% \pm 10 \%$, standard rodent diet). Prior to the administration, mice were fasted for $6 \mathrm{~h}$ with free access to water. Each mouse was administrated with CLE at the dosage of $20 \mathrm{~g} / \mathrm{kg}$ body weight via intragastic gavage. Three hours later, mice were allowed free access to food and water. The body weights, clinical appearances (e.g., behavior modification, skin lesions, and feces) and survival rates of tested mice were recorded in the next 14 days. At the end of the observation, mice were sacrificed after a $12 \mathrm{~h}$ fasting period and dissected for gross examination (including the organs' size, color, consistency, and other characteristics). Based on the GB 15193.3-2014, test material with median lethal dose (LD50) $\geq 20 \mathrm{~g} / \mathrm{kg}$ is defined as practically non-toxic.

\subsection{Statistical Analysis}

The data are presented as means \pm standard error of the means (SEM). All experiments were carried out in triplicate and repeated in three independent sets of experiments. The results were analyzed with SPSS Version 18.0 for Windows using one-way analysis of variance (ANOVA) and post hoc tests (2-sided Dunnett's test) to determine both overall differences and specific differences between each treatment and control. $p$-values $<0.05$ were considered statistically significant.

\section{Conclusions}

This research revealed that polyphenols, soluble sugars, and saponins accounted for approximately $85 \%(w / w)$ of CLE. CLE had excellent antibacterial, anti-inflammatory, and antioxidant activities. EC and PB2 were the key bioactive components in this extract. EC, in particular, contributed to the antibacterial activities of CLE, while PB2 mainly contributed to the anti-inflammatory activities. Both compounds were responsible for the antioxidant activities. Acute oral toxicity tests confirmed that CLE was practically non-toxic. These results provide experimental evidence of the health-beneficial effects of CLE, and indicate the potential for application of CLE as a functional food additive and health supplement in the food and health industries.

Supplementary Materials: The supplementary materials provide information about the detailed process of identification of EC and PB2, as well as the effects of CLE, EC and PB2 on normal RAW 264.7 cells. The following are available online, Figure S1: Effects of CLE, EC and PB2 on normal RAW 264.7 cells.

Author Contributions: Y.G., Y.X. and J.Y. conceived and designed the experiments; Y.G. and X.Z. performed the experiments; Y.G. and Y.X. analyzed the data; Y.G. wrote the paper; Q.D., J.S., Y.T. and J.Y. revised the paper.

Funding: This research was supported by the Natural Science Foundation of Zhejiang (LR17C160001), the National Natural Science Foundation of China (31671861 \& 31872709), and the Innovation Project for Chinese Academy of Agricultural Sciences.

Acknowledgments: Special thanks to Ying Jin for moral support.

Conflicts of Interest: The authors declare no conflict of interest. 


\section{References}

1. Wang, J.; Huang, Y.; Li, K.; Chen, Y.; Vanegas, D.; McLamore, E.S.; Shen, Y. Leaf extract from lithocarpus polystachyus rehd. Promote glycogen synthesis in $\mathrm{t} 2 \mathrm{dm}$ mice. PLoS ONE 2016, 11, e0166557. [CrossRef] [PubMed]

2. Yadav, A.K.; Tangpu, V. Antidiarrheal activity of lithocarpus dealbata and urena lobata extracts: Therapeutic implications. Pharm. Biol. 2007, 45, 223-229. [CrossRef]

3. Khan, M.R.; Kihara, M.; Omoloso, A.D. Antimicrobial activity of lithocarpus celebicus. Fitoterapia 2001, 72, 703-705. [CrossRef]

4. Genco, C.A.; Van Dyke, T.; Amar, S. Animal models for porphyromonas gingivalis-mediated periodontal disease. Trends Microbiol. 1998, 6, 444-449. [CrossRef]

5. Al-Charrakh, A.H.; Al-Khafaji, J.K.; Al-Rubaye, R.H. Prevalence of beta-hemolytic groups c and f streptococci in patients with acute pharyngitis. N. Am. J. Med. Sci. 2011, 3, 129-136. [CrossRef] [PubMed]

6. Wang, L.B.; Shao, M.; Gao, H.Y.; Wu, B.; Wu, L.J. Study on bacteriostasis of fagopyrum cymosum meisn. Chin. J. Microecol. 2005, 17, 330-331.

7. Ci, X.K.; Chen, L.P.; Ou, X.Y. Grape seed proanthocyanidin extracts inhibit lipopolysaccharide of porphyromonas gingivalis. Shanghai J. Stomatol. 2015, 24, 433-436.

8. Sharma, A.; Sati, S.C.; Sati, O.P.; Sati, M.D.; Kothiyal, S.K.; Semwal, D.K.; Mehta, A. A new triterpenoid saponin and antimicrobial activity of ethanolic extract from sapindus mukorossi gaertn. J. Chem. 2013, 2013, 218510.

9. Wang, W.; Chen, R.; Wang, J. Procyanidin b2 ameliorates carrageenan-induced chronic nonbacterial prostatitis in rats via anti-inflammatory and activation of the nrf2 pathway. Biochem. Biophys. Res. Commun. 2017, 493, 794-799. [CrossRef]

10. Martinez-Micaelo, N.; Gonzalez-Abuin, N.; Pinent, M.; Ardevol, A.; Blay, M. Procyanidin b2 inhibits inflammasome-mediated il-1beta production in lipopolysaccharide-stimulated macrophages. Mol. Nutr. Food Res. 2015, 59, 262-269. [CrossRef]

11. Yang, H.; Xiao, L.; Yuan, Y.; Luo, X.; Jiang, M.; Ni, J.; Wang, N. Procyanidin b2 inhibits nlrp3 inflammasome activation in human vascular endothelial cells. Biochem. Pharmacol. 2014, 92, 599-606. [CrossRef] [PubMed]

12. Sung, N.Y.; Yang, M.S.; Song, D.S.; Kim, J.K.; Park, J.H.; Song, B.S.; Park, S.H.; Lee, J.W.; Park, H.J.; Kim, J.H.; et al. Procyanidin dimer b2-mediated irak-m induction negatively regulates tlr4 signaling in macrophages. Biochem. Biophys. Res. Commun. 2013, 438, 122-128. [CrossRef] [PubMed]

13. Zhang, W.Y.; Liu, H.Q.; Xie, K.Q.; Yin, L.L.; Li, Y.; Kwik-Uribe, C.L.; Zhu, X.Z. Procyanidin dimer b2 [epicatechin-(4beta-8)-epicatechin] suppresses the expression of cyclooxygenase-2 in endotoxin-treated monocytic cells. Biochem. Biophys. Res. Commun. 2006, 345, 508-515. [CrossRef]

14. Yang, D.J.; Liu, S.C.; Chen, Y.C.; Hsu, S.H.; Chang, Y.P.; Lin, J.T. Three pathways assess anti-inflammatory response of epicatechin with lipopolysaccharide-mediated macrophage raw264.7 cells. J. Food Biochem. 2015, 39, 334-343. [CrossRef]

15. Hakim, J. Reactive oxygen species and inflammation. Comptes Rendus des Seances de la Societe de Biologie et de ses Filiales 1993, 187, 286-295. [PubMed]

16. O’Brien, J.; Kla, K.M.; Hopkins, I.B.; Malecki, E.A.; McKenna, M.C. Kinetic parameters and lactate dehydrogenase isozyme activities support possible lactate utilization by neurons. Neurochem. Res. 2007, 32, 597-607. [CrossRef] [PubMed]

17. Simos, Y.V.; Verginadis, I.I.; Toliopoulos, I.K.; Velalopoulou, A.P.; Karagounis, I.V.; Karkabounas, S.C.; Evangelou, A.M. Effects of catechin and epicatechin on superoxide dismutase and glutathione peroxidase activity, in vivo. Redox Rep. 2012, 17, 181-186. [CrossRef] [PubMed]

18. Yang, B.Y.; Zhang, X.Y.; Guan, S.W.; Hua, Z.C. Protective effect of procyanidin b2 against ccl4-induced acute liver injury in mice. Molecules 2015, 20, 12250-12265. [CrossRef]

19. Su, H.; Li, Y.; Hu, D.; Xie, L.; Ke, H.; Zheng, X.; Chen, W. Procyanidin b2 ameliorates free fatty acids-induced hepatic steatosis through regulating tfeb-mediated lysosomal pathway and redox state. Free Radic. Biol. Med. 2018, 126, 269-286. [CrossRef]

20. Fu, W.; Sui, D.; Yu, X.; Gou, D.; Zhou, Y.; Xu, H. Protective effects of ginsenoside rg2 against h2o2-induced injury and apoptosis in h9c2 cells. Int. J. Clin. Exp. Med. 2015, 8, 19938-19947. 
21. Wang, Z.J.; Xie, J.H.; Kan, L.J.; Wang, J.Q.; Shen, M.Y.; Li, W.J.; Nie, S.P.; Xie, M.Y. Sulfated polysaccharides from cyclocarya paliurus reduce h2o2-induced oxidative stress in raw264.7 cells. Int. J. Biol. Macromol. 2015, 80, 410-417. [CrossRef] [PubMed]

22. Kruger, N.J. The bradford method for protein quantitation. Methods Mol. Biol. 1994, 32, 9-15. [PubMed]

23. Zhao, Q.D.; Wang, Y.; Shu, L.X.; Song, Z.G.; Li, J.M. Determination of total saponins in anti-inflammatory and antasthmatic extractum. J. Tianjin Univ. Tradit. Chin. Med. 2009, 28, 201-203.

24. Xu, Y.Q.; Hu, X.F.; Tang, P.; Jiang, Y.W.; Yuan, H.B.; Du, Q.Z.; Yin, J.F. The major factors influencing the formation of sediments in reconstituted green tea infusion. Food Chem. 2015, 172, 831-835. [CrossRef] [PubMed]

25. de Freitas, V.A.; Glories, Y.; Laguerre, M. Incidence of molecular structure in oxidation of grape seed procyanidins. J. Agric. Food Chem. 1998, 46, 376-382. [CrossRef]

26. Eloff, J.N. A sensitive and quick microplate method to determine the minimal inhibitory concentration of plant extracts for bacteria. Planta Medica 1998, 64, 711-713. [CrossRef]

27. Gao, Y.; Rankin, G.O.; Tu, Y.; Chen, Y.C. Theaflavin-3, 3'-digallate decreases human ovarian carcinoma ovcar-3 cell-induced angiogenesis via akt and notch-1 pathways, not via mapk pathways. Int. J. Oncol. 2016, 48, 281-292. [CrossRef]

Sample Availability: Samples of Castanopsis lamontii water extract, epicatechin and procyanidin B2 are available from the authors.

(C) 2019 by the authors. Licensee MDPI, Basel, Switzerland. This article is an open access article distributed under the terms and conditions of the Creative Commons Attribution (CC BY) license (http://creativecommons.org/licenses/by/4.0/). 